Interventional Cohort Study

\title{
CT-Guided Transforaminal Epidural Injections with Local Anesthetic, Steroid, and Tramadol for the Treatment of Persistent Lumbar Radicular Pain
}

Mathias Wewalka, MD¹, Ahmadollah Abdelrahimsai, MD², Günther F. Wiesinger, MD³, and Eva Maria Uher, MD'1

\footnotetext{
From: ${ }^{1}$ Landesklinikum Mistelbach, Austria; ${ }^{2}$ Sanatorium Hera, Vienna, Austria; 3 University Hospital Salzburg, Paracelsus Medical University, Salzburg, Austria.

All are members of the Austrian Society of Physical Medicine and Rehabilitation

Dr. Wewalka and Dr. Uher are with the Department of Physical Medicine and Rehabilitation, Landesklinikum Mistelbach, Austria. Dr. Abdelrahimsai is with the Department of Physical Medicine and Rehabilitation, Sanatorium Hera, Viennam Austria.

Dr. Wiesinger is Associate Professor at the Paracelsus Medical University, Salzburg,

Austria.

Address correspondence: Mathias Wewalka MD, MSc

Department of Physical Medicine and Rehabilitation Landesklinikum Mistelbach,

Austria. E-mail: mathias.wewalkamistelbach. Iknoe.at

Disclaimer: There was no external funding in the preparation of this manuscript.

Conflict of interest: None.

Manuscript received: 11/07/2011 Revised manuscript received: $12 / 20 / 2011$

Accepted for publication: $12 / 27 / 2011$

Free full manuscript: www.painphysicianjournal.com
}

Background: A substantial number of patients with persistent lumbar radicular pain are treated with a multimodal spectrum of conservative therapies without lasting effect. The duration of pain is certainly a risk factor for chronification. There is evidence that guided periradicular infiltrations are a valid option in the treatment of radiculopathies. Usually a combination of local anesthetic and/or corticosteroid is injected. Tramadol is being used for perioperative analgesia and has been shown to provide effective, long-lasting pain relief after epidural administration.

Objective: The aim of this pilot study was to evaluate the efficacy of serial CT-guided transforaminal nerve root infiltrations with a supplement of tramadol for patients with persistent, radicular pain.

Study Design: Interventional cohort study.

Setting: Outpatient department for interdisciplinary pain medicine.

Methods: 37 patients who had radicular leg pain for over 9 weeks received up to 3 CTguided transforaminal nerve root infiltrations at intervals of 2 weeks as long as their level of pain was over 3 on a numerical rating scale from 0 to $10.50 \mathrm{mg}$ of Tramadol were added to a combination of local anesthetic (Ropivacain, $2 \mathrm{mg}$ ) and corticosteroid (Triamcinolon, $40 \mathrm{mg}$ ). Evaluations were carried out 24 hours after the Infiltration as well as 2 weeks, 3 and 6 months after the treatment series. The intensity of their radicular pain was measured by a numerical rating scale (NRS). Pain reduction of at least $50 \%$ was defined as successful outcome.

Results: In total, 65 infiltrations were carried out with pain relief in more than $90 \%$ of the patients within 24 hours and an average pain reduction of $64 \%$. Six months post-injection 23 of 34 patients available for follow-up (67.6\%) had a successful pain reduction of $84 \%$ on average. No adverse effects ascribable to the use of tramadol were noted.

Limitations: Due to the lack of a control group we cannot make any statement if tramadol improves short-term pain reduction.

Conclusion: Fast and lasting pain relief is the key to optimize rehabilitation for patients with radicular pain. There is a physiological rationale that the opioid receptors at the spinal level could be used to optimize the analgetic effect of guided periradicular injections. In our case series, serial CT-guided selective nerve root infiltrations with the supplement of tramadol were found to be highly effective in the treatment of persistant radiculopathies. Randomized controlled trials will be necessary to clarify the possible benefit of the supplement of an opioid.

Key words: Serial, nerve root infiltration, tramadol, chronic pain, outcome.

Pain Physician 2012; 15:153-159 
P atients with lumbar radicular pain, who are not severely restricted in their activities of daily life by their pain or have no indication for spinal surgery because of major neurological deficits, are usually treated in an ambulatory setting with a multimodal spectrum of conservative treatments. This includes oral or intravenous (IV) analgesic therapy, physical therapy, transcutaneous electrical nerve stimulation, acupuncture, etc. The level of evidence for any of these treatments is low (1). Although many patients experience adequate pain relief within the first couple of weeks after the first onset, others continue to have substantial radicular pain over a long period. Often patients are then assigned to spinal surgery.

Transforaminal selective nerve root injections (SNRI) for the treatment of lumbar radicular pain have become more and more common in the last years. Meanwhile, there is strong to moderate evidence for this method (2-3). Riew et al (5) reported that the majority of patients with lumbar radicular pain who avoid an operation for at least one year after receiving a nerve root injection will continue to avoid operative intervention for a minimum of 5 years. In general, fluoroscopy is used as a guiding technique while a combination of local anesthetic and corticosteroid is injected near the affected nerve root (6). In various studies, the rate of patients with short to moderate term pain relief because of this technique has been reported from $55 \%$ up to $84 \%(5,4-13)$. With the growing availability of computed tomography (CT), CT-guided infiltrations have become more common in the treatment of radicular pain syndromes. Use of intermittent CT fluoroscopy during lumbar selective nerve root blocks can result in minimal radiation dose levels and procedure times that are comparable to fluoroscopic guidance (5). The kind of drugs being used for this type of intervention have hardly changed over the last decades.

The presence of opioid receptors at the spinal level has been well known for many years. Stein et al (15) summarized that injury and inflammation leads to the increased synthesis of opioid receptors in dorsal root ganglion neurons (6). Tramadol has a lower affinity to opioid receptors than others, mainly on $\mu$-receptors, but it also inhibits the reuptake of serotonin and noradrenalin. In its IV administration form, it is a well established analgesic whose epidural application has been shown to be safe and effective for pain relief, especially in postoperative pain care (7-18). The rationale for this pilot study was to improve a well estab- lished procedure in terms of the amount and duration of pain reduction. This study retrospectively observes the degree and duration of pain relief achieved by combining tramadol with local anesthetic and corticosteroid in a cohort practice audit.

\section{Methods}

\section{Study Design}

Cohort study

\section{Participants}

Over a 2-year period, patients with lumbar radicular pain were recruited from our outpatient clinic. Eligible patients had already been treated by their general practitioner or orthopedic specialist. Pain radiating into the lower limb had to be strictly monosegmental and persistent for at least 9 weeks despite continual conservative treatment with oral or IV analgesics and physical therapy. Oral medication with World Health Organization class II analgesics had to be established for at least 3 weeks. The intensity of pain had to be at least 3 on the 0-10 numeric rating scale (NRS)(8). A minor numbness or weakness in the corresponding dermatome or the segment-indicating muscle was tolerated. In the magnetic resonance imaging scan there had to be a clear morphologic correlative for the clinically affected nerve root in the form of a discal protrusion/herniation and/or bony stenosis of the neuroforamen because of hypertrophic facet joints. Exclusion criteria were: indication for immediate spinal surgery because of a relevant neurological deficit, prior spinal surgery, pain or sensory alteration in the lower limb due to other reasons (arthrosis, peripheral vascular disease, polyneuropathy), diabetes, relevant co-morbidity (Kaplan-Feinstein Score $\geq 2$ ), oral anticoagulatiuon and known adverse reactions to the medication used. Patients who did not respond to the first injection with a pain reduction of at least $50 \%$ within the first 2 hours were also excluded, as this was considered to be a negative diagnostic sign. These patients were reevaluated for their possible origin of pain and in the majority of cases received further diagnostic injections. Thirty-seven patients ( 16 men and 21 women) were selected for this study. The average age was $59 \pm 13$ years and the average body mass index was $27.5 \pm 4$. The initial pain level was $6.6 \pm 1.5$ NRS on average. The mean duration of radicular pain in the lower limb before the intervention was $12.3 \pm 2.4$ weeks. Written consent was obtained from all patients prior to the injections. 


\section{Intervention}

Patients received a CT-guided periradicular injection of the affected nerve root in an outpatient setting. In cases of S1 radiculopathies, the needle was placed into the foramen at $\mathrm{S} 1$ even if the morphologic correlative was at the level of the L5/S1 disc. Correct needle placement and periradicular diffusion was verified by application of $0.5 \mathrm{~mL}$ of a contrast agent. Consequently, a combination of $2 \mathrm{mg}$ ropivacaine, $40 \mathrm{mg}$ triamcinilone and $50 \mathrm{mg}$ tramadol, adding up to a total fluid volume of $2.5 \mathrm{~mL}$, was injected into the neuroforamen. Patients then remained under observation for 2 hours. Any adverse effects during or after the injection were noted.

\section{Assessment}

The main outcome parameter was radicular pain in the lower limb measured by the NRS. Patients were evaluated at 24 hours and 2 weeks following the injection. Two weeks after the first treatment, if the pain level was still $>3$, then another CT-guided injection was carried out the next day. Following this algorithm, patients received up to 3 SNRIs in intervals of 2 weeks as long as their pain level was $>3$. Further evaluations were scheduled 2 weeks, as well as 3 and 6 months after the last infiltration. Patients were also asked whether they had changed their amount of pain medication.
They received no other treatment during the observation period. Analgetic medication could be continued as before if needed. Patients who needed an increase in analgesics or any other treatment for radicular pain during this time were rated as treatment failures. A successful outcome was achieved at the time of followup if patients reported $\geq 50 \%$ overall subjective pain relief. In some cases interventions and evaluations were carried out by the same medical staff, but the assessment was strictly standardized.

\section{Statistical Analysis}

Demographic data are presented as mean and standard deviations (SDs). Paired t-tests were used to evaluate the changes in pain levels. The level of significance was set at $P<0.05$. The Wilcoxon rank-sum test was used to assess differences in outcome measures related to differences in sex, age, initial pain level, or duration of pain.

\section{Results}

The 37 patients included in the cohort had a total of 65 separate injection sessions. Two weeks after the first intervention, 17 of the 37 patients had a pain score $\leq 3$ and needed no further injections. The other 20 were scheduled for a second injection the next day;

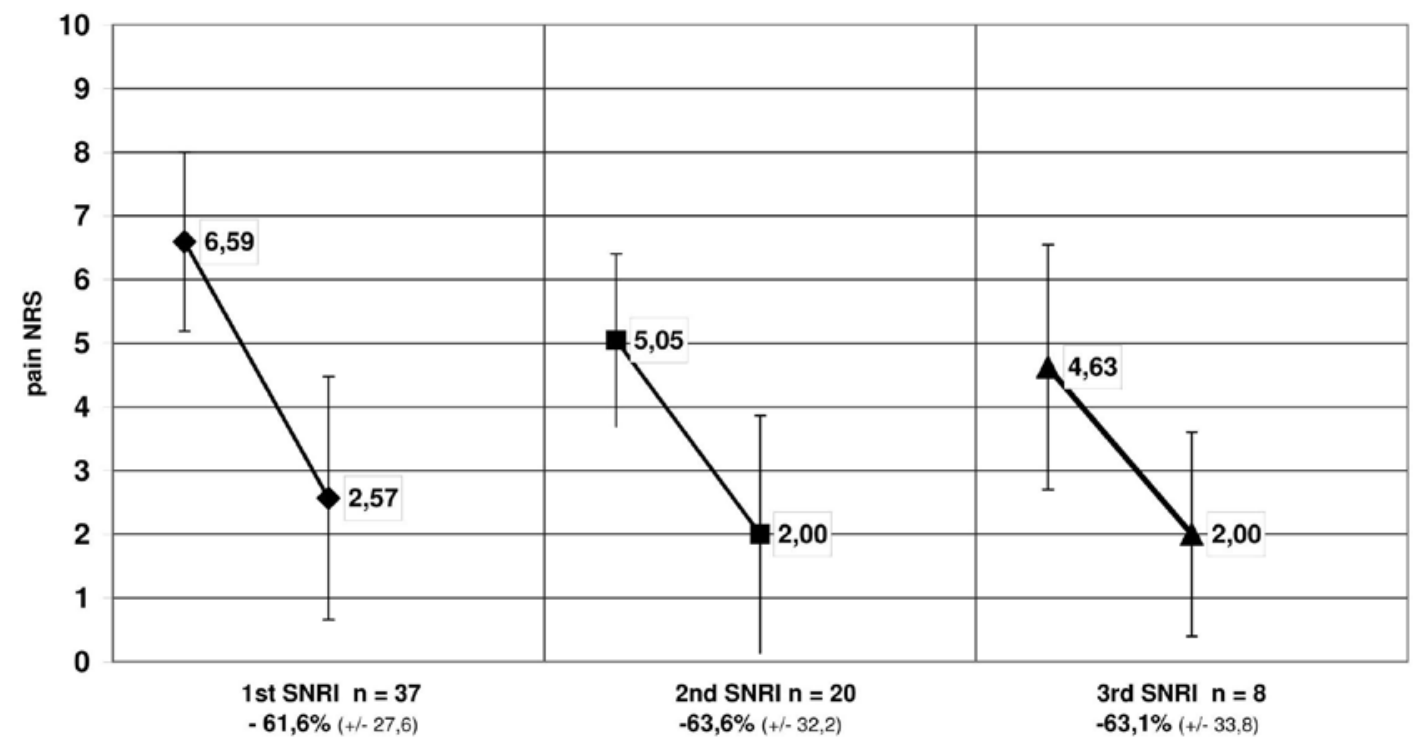

Fig.1. SNRI with tramadol - 24 hour pain reduction. 
of those, 8 received a third injection 2 weeks later. Mean pain values before and after each intervention, as well as the rate of pain relief for each series, are displayed in Fig. 1. After 24 hours, the average pain reduction for all 65 injections was $62.1 \% \pm 28.9 \%(P$ $<0.0009)$. The first infiltration series was significantly more effective in terms of absolute pain reduction $(P<$ 0.017 ) but there was no significant difference among the first, second, and third injections in terms of pain reduction relative to the pain level before. We could not find any correlation among the amount of shortterm pain reduction, duration of pain, or demographic baseline data. Minor adverse effects were recorded in 19 of the 65 interventions. Three patients had a minor transient weakness of the key muscle of no more than 3 to 4 hours according to the spinal level of the injection. This is a well known side effect due to the use of a local anesthetic. Fourteen patients reported slightly increased low back pain, which occurred about 4 to 5 hours after the intervention but did not last more than 24 hours. Two patients had an episode of low blood pressure immediately after their injection. They received an infusion with saline and recovered within minutes. No adverse effects ascribable to the use of tramadol (nausea, vomiting, respiratory depression) were noted.

Further evaluations were carried out 2 weeks after the patients' last injections as well as 3 and 6 months later. At 3 months, one patient was lost to follow-up and 5 patients were rated as treatment failures due to the lack of pain reduction or the need for further treatment for their radicular pain. At 6 months, 3 patients were lost to follow-up; 2 had insufficient pain reduction and 6 had to undertake further treatment and so were rated as treatment failures. Success/failure rates and pain values for long-term follow-up are displayed in Fig. 2. In addition, all patients who had successful pain reduction were taking less or no pain medication.

At long-term follow-up, there was no significant difference in age, sex or initial pain level among the patients with successful outcomes and those with treatment failures. Six months after the intervention(s) $67.6 \%$ of our patients had a successful outcome with a mean pain score of 1.00 . There was a weak correlation between treatment failure and a higher number of infiltrations $(P=0.085)$. All short-term and long-term improvements to baseline pain values were highly significant $(P<0.001)$.

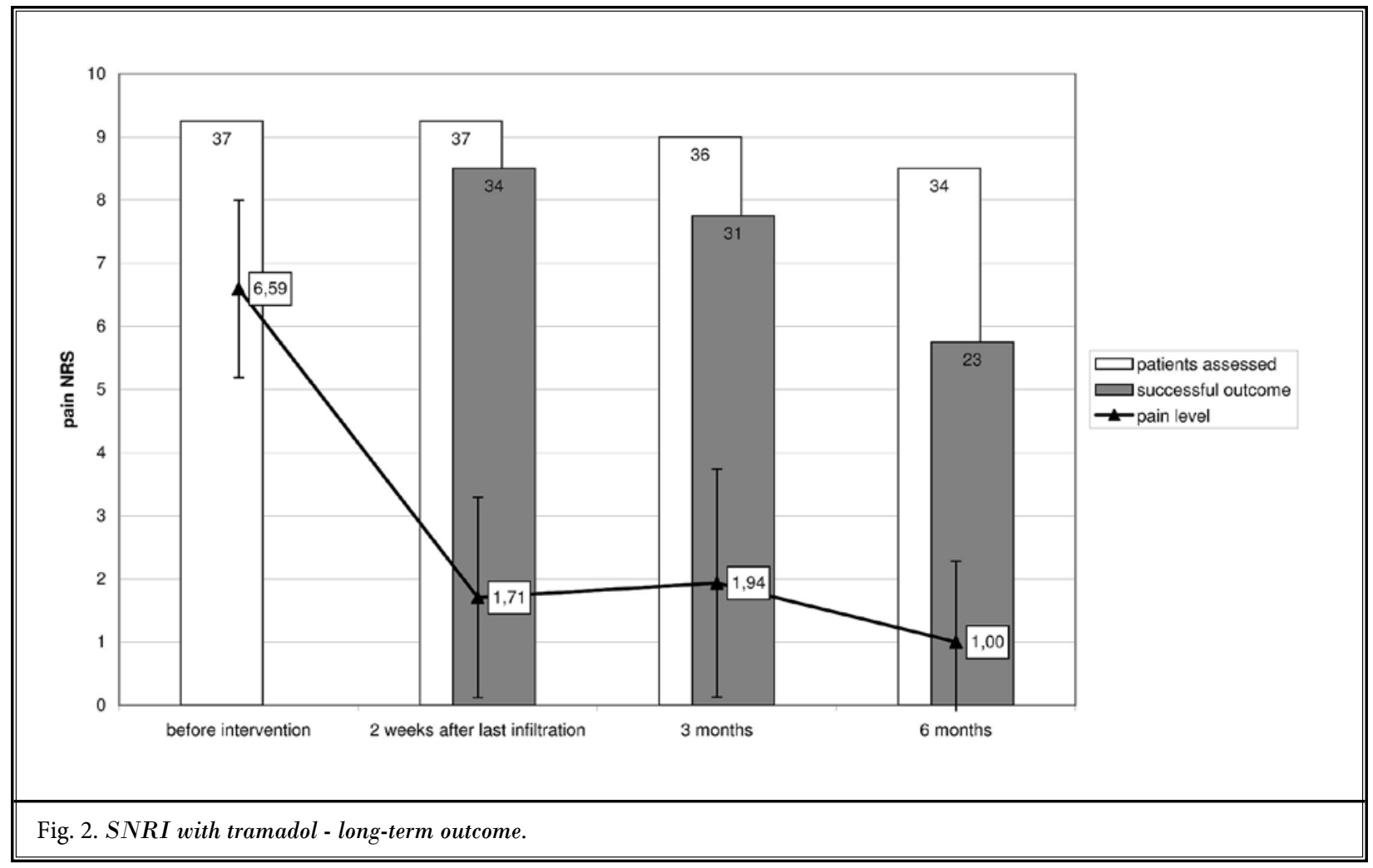




\section{Discussion}

In our outpatient clinic we are seeing many patients with radicular pain syndromes who have been unsuccessfully treated with various conservative modalities over a long period. There is widespread consent that the duration of pain is a risk factor for chronification. The basic technique and the drugs which are routinely used for guided nerve root infiltrations have not changed by much in the last decades. Certainly the procedure times and radiation doses have been significantly reduced by the use of modern radiological equipment. While the transforaminal approach for selective nerve root infiltrations seems to be the most widely used, there has been some research comparing it to the interlaminar approach. Two of 3 trials which directly compared these techniques reported a minor advantage, at least initially, for transforaminal epidural steroid injections over the interlaminar approach (9-22). The caudal approach is deemed effective but is mostly chosen if there is a bilateral radiation of radicular pain into the lower extremities (e.g., due to spinal stenosis from a medial herniation or a listhesis) (10). In a retrospective comparison, Lee et al (11) concluded that the transforaminal and translaminar procedures were more effective than a caudal approach. The choice of drugs used for this kind of intervention remains controversial. Although a combination of local anesthetic and corticosteroid is used in most of the therapeutic injections in the area of the lumbar spine, there is, at least for transforaminal injections for radicular leg pain, no clear evidence that the supplement of a corticosteroid is in fact superior to the use of a local anesthetic alone (12). Tachihara et al (13) could reproduce this perception in a rat model and found no additional decrease of TNF-alpha in the dorsal root ganglion by a corticosteroid.

Any such procedure should be routinely scrutinized for possible improvements. The aim of this pilot study was to monitor the short- and moderate-term effects of selective nerve root blocks with the addition of tramadol in patients who had ineffective conservative treatment over a long time. In order to reduce the possibility of false negative results, we chose a precise infiltration technique and a selected group of patients whose major complaint was persistent and strictly monosegmental radicular leg pain correlating with a clear radiographic finding. As some studies suggested that multiple injections may produce a more sustained effect $(5,9)$, patients received up to 3 SNRIs in intervals of 2 weeks until a satisfactory pain reduction (NRS $\leq 3$ ) was achieved.
The rationale for the use of tramadol was to enhance and extend the primary inhibition of the painspasm cycle and reverberating nociceptor transmission(14) at the spinal level by addressing local opioid receptors until the corticosteroid fully unfolds its membrane-stabilizing and anti-inflammatory effect (15-30) . In an experimental trial on animals, Dehkordi et al (16) compared the short-term analgesic effect of epidural lidocaine alone versus lidocaine plus tramadol, and concluded that the supplement of the opioid shortens the time of onset and extends the anagesic effect. After 24 hours the patients in our trial reported a mean pain reduction of over $60 \%$, whether it was the first, second, or third injection. Absolute and relative short-term pain values within 24 hours were lower than those recorded in the studies of Karpinnen et al(6) and $\mathrm{Ng}$ et al(13). Despite the similarities of the treatment groups and the interventional properties of these studies and ours, the results can only be interpreted as an impetus for further controlled trials. The major drawback of this study was, of course, the lack of a direct control group. As interventions and evaluations were in some cases carried out by the same medical staff, we cannot rule out any observer bias, but due to the results, we believe that this does not alter the interpretation of our findings.

Moderate-term values for radicular leg pain, as well as failure rates, were comparable to recent studies in this field of pain therapy. Nevertheless, two-thirds of the patients who had previously been treated to no avail by conservative means had a highly effective and persistent pain reduction.

So far there is no record of the use of opioids in nerve root infiltrations for the treatment of radicular leg pain. The rate of minor adverse effects in our group of patients was within known limits and we did not record any adverse effects ascribable to tramadol. The majority of patients reported a reduction of their oral pain medication, which is an additional positive aspect.

\section{Conclusion}

In our study serial transforaminal nerve root infiltrations with local anesthetic, corticosteroid, and tramadol were highly effective in the treatment of radiculopathies, even if patients had been unsuccessfully treated by conservative means over a long period before. Fast and lasting pain relief is the key to optimize rehabilitation for patients with radicular pain. Although spinal surgery has made huge progress in recent years, the improvement of nonsurgical treatments for patients with radicular pain should be promoted. The use of opioids 
for this kind of intervention has a certain rationale. Further randomized controlled trials will be necessary to clarify the possible benefit.

\section{Acknowledgements}

The authors wish to thank the editors of Pain Physician for their review and constructive criticism in improving the manuscript.

\section{References}

1. Luijsterburg PA, Verhagen AP, Ostelo RW, van Os TA, Peul WC, Koes BW. Effectiveness of conservative treatments for the lumbosacral radicular syndrome: A systematic review. Eur Spine J 2007; 16:881-899. Epub 2007 Apr 6.

2. Benny B, Azari P. The efficacy of lumbosacral transforaminal epidural steroid injections: A comprehensive literature review. J Back Musculoskelet Rehabil 2011; 24:67-76.

3. Boswell MV, Trescot AM, Datta S, Schultz DM, Hansen HC, Abdi S, Sehgal N, Shah RV, Singh V, Benyamin RM, Patel VB, Buenaventura RM, Colson JD, Cordner HJ, Epter RS, Jasper JF, Dunbar EE, Atluri SL, Bowman RC, Deer TR, Swicegood JR, Staats PS, Smith HS, Burton AW, Kloth DS, Giordano J, Manchikanti L Interventional techniques: Evidencebased practice guidelines in the management of chronic spinal pain. Pain Physician 2007; 10:7-111.

4. Roberts ST, Willick SE, Rho ME, Rittenberg JD. Efficacy of lumbosacral transforaminal epidural steroid injections: A systematic review. PM R 2009; 1:657-668.

5. Riew KD, Park JB, Cho YS, Gilula L, Patel A, Lenke LG, Bridwell KH. Nerve root blocks in the treatment of lumbar radicular pain. A minimum five-year followup. J Bone Joint Surg Am 2006 ;88:17221725 .

6. Derby R, Bogduk N, Anat D, Kine G: Precision percutaneous blocking procedures for localizing spine pain. Part 2. Pain Digest 1993; 3:175-178.

7. Karppinen J, Malmivaara A, Kurunlahti $M$, Kyllönen E, Pienimäki T, Nieminen $\mathrm{P}$, Ohinmaa A, Tervonen O, Vanharanta $H$. Periradicular infiltration for sciatica: A randomized controlled trial. Spine (Phila Pa 1976) 2001; 26:1059-1067.

8. Weiner BK, Fraser RD. Foraminal injection for lateral lumbar disc herniation. J Bone Joint Surg 1997; 79:804-807.

9. Devulder, J. Transforaminal nerve root sleeve injection with corticosteroids, hyaluronidase, and local anesthetic in the failed back surgery syndrome. J Spinal Disord 1998; 11:151-154.

10. Lutz GE, Vad VB, Wisneski RJ. Fluoroscopic transforaminal lumbar epidural steroids: An outcome study. Arch Phys Med Rehabil 1998; 79:1362-1366.

11. Manchikanti L, Pakanati RR, Pampati V. Comparison of three routes of epidural steroid injections in low back pain. Pain Digest 1999; 9:277-285.

12. Vad VB, Bhat AL, Lutz GE, Cammisa F. Transforaminal epidural steroid injections in lumbosacral radiculopathy: A prospective randomized study. Spine ( $\mathrm{Ph}$ ila Pa 1976) 2002; 27:11-16.

13. Ng L, Chaudhary N, Sell P. The efficacy of corticosteroids in periradicular infiltration for chronic radicular pain: A randomized, double-blind, controlled trial. Spine (Phila Pa 1976) 2005; 30:857-862.

14. Wagner AL. Selective lumbar nerve root blocks with CT fluoroscopic guidance:Technique, results, procedure time, and radiation dose. AJNR Am J Neuroradiol 2004; 25:1592-1594.

15. Stein C, Lang LJ. Peripheral mechanisms of opioid analgesia. Curr Opin Pharmacol 2009;9:3-8. Epub 2009 Jan 20.

16. Senel AC, Akyol A, Dohman D, Solak M. Caudal bupivacaine-tramadol combination for postoperative analgesia in pediatric herniorrhaphy. Acta Anaesthesiol Scand 2001; 45:786-789.

17. Siddik-Sayyid S, Aouad-Maroun M, Sleiman D, Sfeir M, Baraka A. Epidural tramadol for postoperative pain after Cesarean section. Can J Anaesth 1999; 46:731735 .

18. Demiraran Y, Kocaman B, Akman RY. A comparison of the postoperative analgesic efficacy of single-dose epidural tramadol versus morphine in children. $\mathrm{Br}$ ] Anaesth 2005; 95:510-513. Epub 2005 Aug 12.

19. Huskisson, E. C. Measurement of pain. Lancet 1974; 2:1127-1131.

20. Schaufele MK, Hatch L, Jones W. Interlaminar versus transforaminal epidur- al injections for the treatment of symptomatic lumbar intervertebral disc herniations. Pain Physician 2006; 9:361-366.

21. Rados I, Sakic K, Fingler M, Kapural L. Efficacy of interlaminar vs transforaminal epidural steroid injection for the treatment of chronic unilateral radicular pain: Prospective, randomized study. Pain Med 2011; 12:1316-1321.

22. Gharibo CG, Varlotta GP, Rhame EE, Liu EC, Bendo JA, Perloff MD. Interlaminar versus transforaminal epidural steroids for the treatment of subacute lumbar radicular pain: A randomized, blinded, prospective outcome study. Pain Physician 2011; 14:499-511.

23. Botwin K, Brown LA, Fishman M, Rao S. Fluoroscopically guided caudal epidural steroid injections in degenerative lumbar spine stenosis. Pain Physician 2007; 10:547-558.

24. Lee JH, Moon J, Lee SH. Comparison of effectiveness according to different approaches of epidural steroid injection in lumbosacral herniated disk and spinal stenosis. J Back Musculoskelet Rehabil 2009; 22:83-89.

25. Buenaventura RM, Datta S, Abdi S, Smith HS. Systematic review of therapeutic lumbar transforaminal epidural steroid injections. Pain Physician 2009; 12:233-251.

26. Tachihara $H$, Sekiguchi $M$, Kikuchi $S$, Konno S. Do corticosteroids produce additional benefit in nerve root infiltration for lumbar disc herniation? Spine (Phila Pa 1976) 2008; 33:743-747.

27. McCormack K. Signal transduction in neuropathic pain, with special emphasis on the analgesic role of opioids -Part II: Moving basic science towards a new pharmacotherapy. Pain Rev 1999; 6:99131.

28. Devor M, Govrin-Lippmann R, Raber P. Corticosteroids suppress ectopic neural discharge originating in experimental neuromas. Pain 1985; 22:127-137.

29. Johansson A, Hao J, Sjolund B. Local corticosteroid application blocks trans- 
mission in normal nociceptor C-fibers. Acta Anaesthesiol Scand 1990; 34:335-338.

30. Muramoto T, Atsuta $\mathrm{Y}$, Iwahara $\mathrm{T}$, Sato

M, Takemitsu Y. The action of prosta- glandin E2 and triamcinolone acetonide on the firing activity of lumbar nerve roots. Int Orthop 1997; 21:172-175.
31. Dehkordi SH, Bigham-Sadegh A, Gerami R. Evaluation of anti-nociceptive effect of epidural tramadol, tramadol-lidocaine and lidocaine in goats. Vet Anaesth Analg 2012; 39:106-110. 
